\title{
Stability Analysis and Parameter Optimization of Deep Excavation Supporting System in Granular Soils
}

\author{
Manman Dong ${ }^{1}$ and Pengjiao Jia (iD ${ }^{2}$ \\ ${ }^{1}$ Faculty of Engineering, China University of Geosciences, Wuhan, Hubei, China \\ ${ }^{2}$ School of Resources and Civil Engineering, Northeastern University, Shenyang 110819, China \\ Correspondence should be addressed to Pengjiao Jia; jpengjiao@163.com
}

Received 28 June 2020; Accepted 5 August 2020; Published 19 August 2020

Academic Editor: Peixin Shi

Copyright (c) 2020 Manman Dong and Pengjiao Jia. This is an open access article distributed under the Creative Commons Attribution License, which permits unrestricted use, distribution, and reproduction in any medium, provided the original work is properly cited.

\begin{abstract}
Deep excavations are prone to result in excessive ground surface settlement displacement of surrounding existing structures, which could cause severe economic damage, even casualties. Hence, the optimization of pile parameters and evaluation of the stability of the excavation are of paramount importance. This paper aims to evaluate the security of deep excavation and optimize the parameters of supported piles in granular soils. An excavation case in granular soils is used to evaluate the stability of deep excavation using displacement least squares method. The stability of case history, Changqingqiao subway station, using pile and inner support system is evaluated by using the least square method. Subsequently, the finite element method is used to optimize the critical parameters of the supported piles, and it needs to be emphasized that the correctness and reasonability of the finite element (FE) models are evaluated according to field measurements. The optimum pile diameter and embedment ratio for singleand double-row retaining pile are $1.0 \mathrm{~m}$ and 0.4 . The maximum vertical displacement of surrounding soil and horizontal displacement of piles can be calculated by the equations obtained in this research which can provide useful guidance for the designing of deep excavation.
\end{abstract}

\section{Introduction}

With the proliferation of high-rise building and subway construction, deep excavations are commonplace in day-today geotechnical engineering projects. Deep excavations are prone to resulting in problems such as excessive ground surface settlement $[1,2]$ (both horizontal and vertical), excessive displacement of surrounding facilities (e.g., underground pipeline [3, 4], buildings [5], and tunnels [6, 7]) which could result in high economic damage and even loss of lives. Therefore, the correct estimation of the ground displacements and evaluation of the stability of the excavation are of paramount importance.

Different approaches (e.g., soldier pile walls, tieback wall, and diaphragm wall) are available for guaranteeing the stabilization of deep excavations and limiting the ensuing ground displacements. Pile tieback walls have been widely adopted in propped excavation because of convenient construction, low cost, and high performance $[8,9]$. In the past decades, the performance of soldier pile walls and ground surface settlement has been investigated by several researchers.

Roboski and Finno [10] proposed a performance-based relation to estimating the maximum horizontal ground movements for flexible wall systems as a function of a factor of safety against basal heave and excavation depth. Hashash et al. [11] collected lateral deformations and surface settlements for three construction contracts, and their data showed that surface settlements, although small, extended farther away from the excavation than previously reported. Wei and Tan [12] investigated the performance of the deep excavation and the associated effect on the adjacent utility pipelines, and deflections of pile walls, ground surface settlements, and deflection of the existing structures. Momeni et al. [13] analyzed the reliability of deep excavations by using Random Set (RS) theory and Monte Carlo 
(MC) technology. Huang et al. [14] provided a new failure mechanism to estimate the basal stability of excavations with embedded walls in un-drained clay based on the upper bound theorem. Han et al. [6] proposed a risk assessment methodology to estimate the risks of circumferential cracks of the existing tunnel induced by deep excavation. Han et al. [15] investigated the design process and mechanical performances of deep excavation retained by tieback anchored pile walls using the finite element method and the elastic theory. Chen et al. [16] derived ground surface settlement law caused by the combined influence of excavation and dewatering in granular area. In addition, overexcavation (i.e., removing more soil than designed) and a long construction duration caused the pile walls to develop further deformation. The applications of observation methods have been reported in some literature, e.g., Yeow et al. [17], Spross and Johansson [18], Jia et al. [19, 20], Fuentes et al. [21], and Alipour and Eslami [22]. Subsequently, Prat [23], Lim and $\mathrm{Ou}$ [24], and $\mathrm{Ni}$ et al. [25] discussed a selection of appropriate soil parameters for deflection and ground settlement analysis of deep excavations using numerical simulations. However, the evaluation method for the stability of deep excavation induced by construction is scarce in the abovementioned literature, especially for deep excavation in granular soils.

In this investigation, displacement least squares method is proposed to conduct a real-time evaluation of the stability of the excavation. The horizontal displacement of retaining piles is delineated along with the excavation depth, while the ground settlement is recorded with the excavation time. In addition, a series of the FE models is established and evaluated by the field measurements, and it needs to be emphasized that the soil parameters used in FE models are obtained through triaxial tests. Subsequently, the soil Earth pressure distribution at different excavation stages and optimized pile parameters is investigated.

\section{Project Overview}

The Changqingqiao subway station case is located in Shenyang, China, and selected to investigate the mitigation of structure and soil deformation during excavation. The deep excavation and the supporting system are shown in Figure 1(a). It is a rectangular shape deep excavation with pile and inner supporting system. Reinforced concrete is between the retaining piles to ensure the stability of excavation. The width, length, and depth of the station are $25.3 \mathrm{~m}, 148.4 \mathrm{~m}$, and $22.4 \mathrm{~m}$, respectively. The whole construction period is 18 months. Bored grouting piles were employed as the retaining piles according to the hydrogeological and engineering geological profile of the study place. The pile length is $L=33 \mathrm{~m}$, and the pile diameter is $r=1000 \mathrm{~mm}$ with a centre distance of $d=1400 \mathrm{~mm}$. The reinforced concrete spray is $100 \mathrm{~mm}$ in thickness. 39 pumping wells with a diameter of $429 \mathrm{~mm}$ are prepared every $10 \mathrm{~m}$ along the excavation side for the groundwater pumping. The wells keep pumping for 10 days until the groundwater level is close to the bottom layer of the excavation. Four-layer inner bracing structures are installed with the excavation process. The properties of the supporting system are shown in Table 1. The profiles of the supporting system and layer distribution are shown in Figure 1(b).

\section{Stability Evaluation of the Deep Excavation}

3.1. Monitoring Schedule. To make sure of the stability of deep excavation, monitoring points are usually arranged in the construction of deep excavation. In this investigation, Figure 2 shows their final configuration as recorded at each of the following monitoring sections at steady-state conditions. There are five monitoring intersections around the deep excavation to measure the ground settlement, that is, A1-A18, B1-B18, C1-C18, D1-D18, and E1-E18. Moreover, 18 monitoring points are used to predicate the horizontal displacement of retaining piles.

3.2. Description of DLSM. A least square method is an optimization method by minimizing the sum of the squares of the errors to the matching function of the data which is widely used in the statistic optimization problem. As indicated in Figure 3, the control value can be constant or variable to minimize the discrepancy between random values and control values. The idea of the least square method is adopted to evaluate the stability of deep excavation, that is, displacement least squares method (DLSM). The monitored displacement can be fitted by minimizing the sum of the squares of the errors between the fitting displacement and the monitored displacement. The quintic polynomial is adopted to conduct the curve fitting of the displacement of supporting structures and ground settlement.

The monitored displacement with respect to monitoring time or distance can be recorded as $\left(x_{i}, y_{i}\right)$, where $x_{i}$ is the monitoring time or displacement and $y_{i}$ is the vertical or lateral displacement. The best-fitting function can be expressed as

$$
f_{f}(\chi)=\sum_{i=1}^{n} c_{i} f_{f 1}(\chi)=c_{1} f_{f 1}(\chi)+c_{2} f_{f 1}(\chi)+\cdots+c_{n} f_{f 1}(\chi),
$$

where $c_{i}$ is the weight factor of the fitting function and $f_{\mathrm{f}}$ is the fitting function.

The essence of the DLSM is obtaining the best fitting function to yield the minimum value of the square of the errors between the fitting and monitored displacement. The errors can be obtained as follows:

$$
\|\delta\|^{2}=\min \sum_{i=1}^{n} \omega_{i}\left[f_{f i}(\chi)-f_{m i}(\chi)\right]^{2} .
$$

The deviation between monitored value and fitting value $\left(\delta_{i}=y_{i}-y_{i}\right.$, fitting $)$ is usually distributed, which is also proved by Wang et al. [26]. Principles of Statistics are introduced to calculate the mean value of deviation factor $\mu$ and standard deviation $\sigma$ between monitored value and fitting value. The centreline of the control diagram is set to be CL (Control Line), RCL (Right Control Line), and LCL (Left Control 

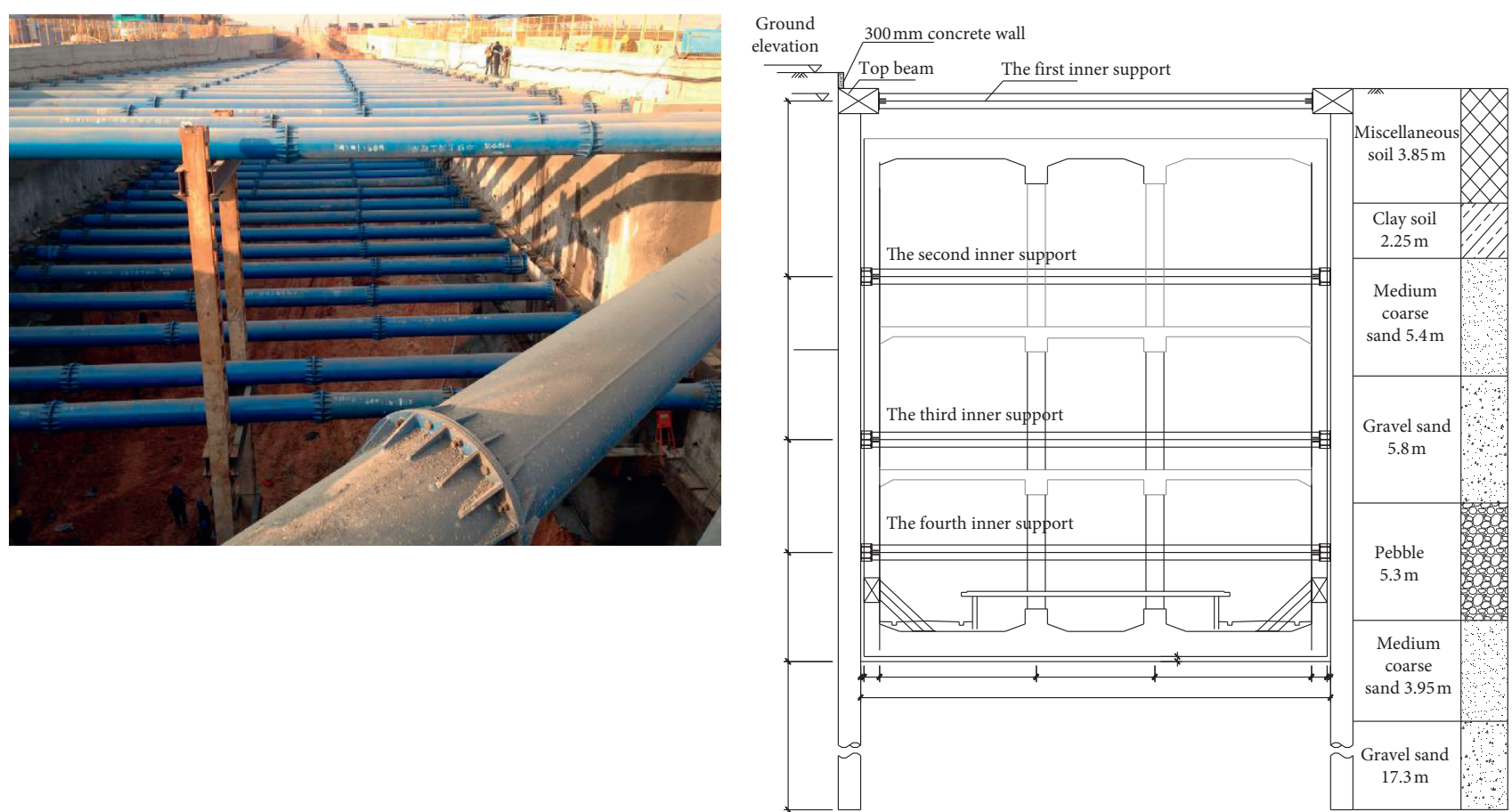

(a)

(b)

Figure 1: The profile of the supporting system and layer distribution. (a) The in situ construction profile. (b) The cross-section profile [13].

TABLe 1: Parameters of the supporting system.

\begin{tabular}{lccc}
\hline Inner support & Depth $(\mathrm{m})$ & Diameter $(\mathrm{mm})$ & Pipe thickness $(\mathrm{mm})$ \\
\hline First layer & 7 & 609 & 12 \\
Second layer & 13.5 & 609 & 16 \\
Third layer & 18 & 800 & 16 \\
Fourth layer & 22.4 & 800 & 12 \\
Inverse strut & Corner & 609 & 12 \\
\hline
\end{tabular}

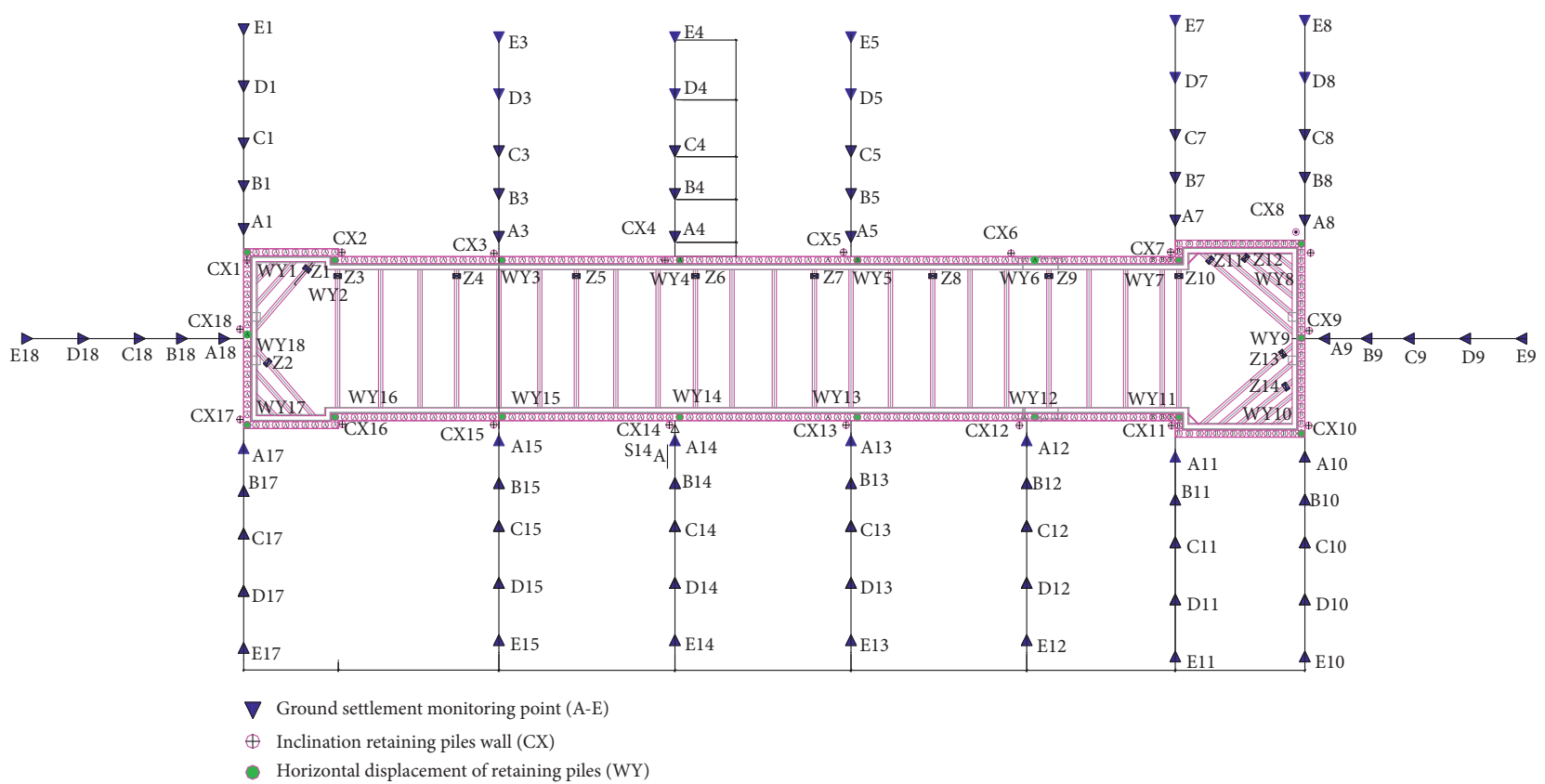

FIGURE 2: Layout of monitoring points around the deep excavation. 


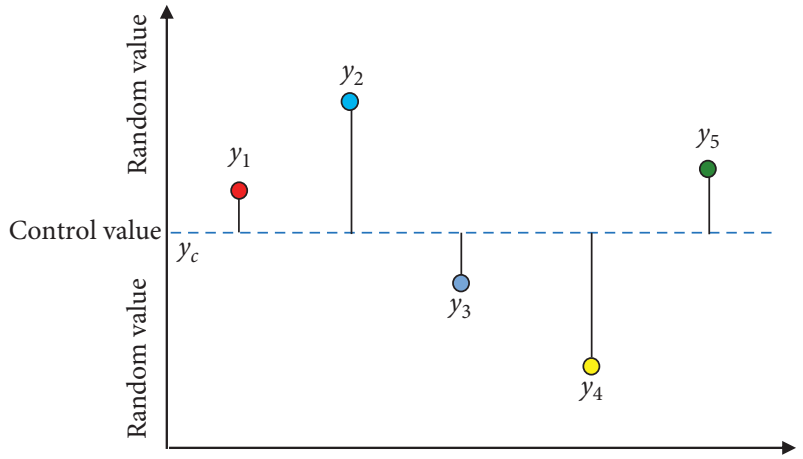

(a)

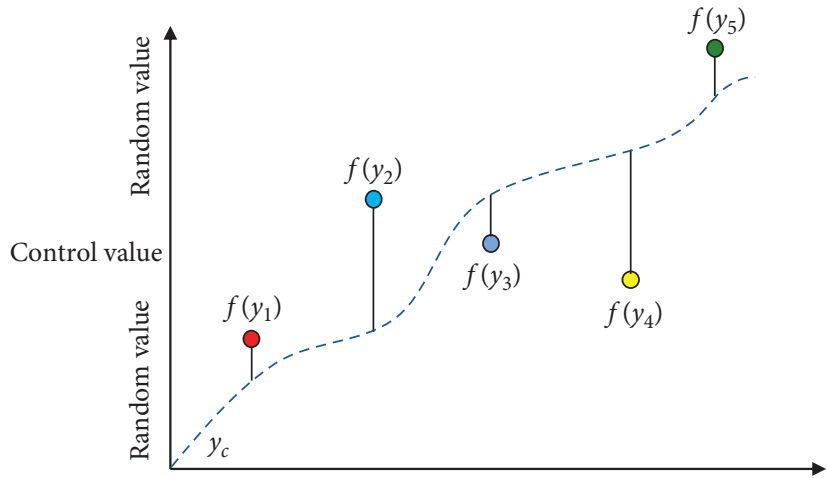

(b)

Figure 3: The schematic diagram of the least square method.

Line). $3 \sigma$ criteria in normal distribution represent that the probability of values within the range (from $\mu-3 \sigma$ to $\mu+3 \sigma$ ) is 0.9974, and the following rules can be defined based on $3 \sigma$ criteria:

$$
\left\{\begin{array}{l}
C L=\mu, \\
R C L=\mu+3 \sigma, \\
L C L=\mu-3 \sigma .
\end{array}\right.
$$

When the mean value of deviation $\mu=0$, the standard deviation is shown as

$$
\sigma=\sqrt{\frac{1}{m} \sum_{i=1}^{m} \delta_{i}^{2} .}
$$

3.3. Horizontal Displacement of Retaining Piles. The ground settlement is closely related to the supporting system, material, and the surrounding soil properties. The ground settlement along the excavation side can be estimated by the soil loss theory. The horizontal displacement of deep excavation obeys parabolic shape distribution; the relationship between maximum ground settlement $\left(\delta_{\mathrm{vmax}}\right)$ and horizontal displacement $\left(\delta_{\mathrm{hmax}}\right)$ is linearly related:

$$
\delta_{v \max }=1.18 \delta_{h \max } .
$$

The relationship between the ground settlement at any point and the maximum ground settlement is

$$
\delta_{v}=\delta_{v \max } \exp \left[-0.25(x-0.93)^{2}\right],
$$

where $\delta_{v}$ represents the ground settlement at any point and $x$ represents the vertical distance between monitoring point and deep excavation side.

The horizontal displacement of retaining piles CX1, CX2, CX4, CX5, CX7, CX8 varying with depth is depicted in Figure 4 . The maximum horizontal displacement occurs at the middle of the excavation side, which is at CX4 and CX5. The horizontal displacement of piles decreases with the increase of distance from the pile centre. The displacement at the corner of excavation, especially at CX1 and CX8, shows a reverse direction compared with the piles along the excavation sides. The maximum deformation is $8.32 \mathrm{~mm}$. The reason for this phenomenon is that the inclined brace at the excavation corner can effectively prevent the displacement of soils. The horizontal displacement of all the retaining piles is under the control value of $50 \mathrm{~mm}$, which means that the deep excavation is safe under this supporting system.

As is indicated in Figure 4, the horizontal displacement of retaining piles along the excavation depth is in a parabolic shape. The relationship between monitored displacement $\left(y_{\mathrm{i}}\right)$ and the monitoring depth $\left(x_{\mathrm{i}}\right)$ is collected as $\left(x_{\mathrm{i}}, y_{\mathrm{i}}\right)$. The least square method is used for linear-fitting the horizontal displacement of piles. Control diagram is introduced to monitor and give an early warning for the outliers during the excavation. The quintic polynomial equation can fit the monitoring data perfectly with a correlation coefficient over 0.9. The quintic polynomial expression is shown as

$$
y=9.15 e^{-6} x^{5}-5.13 e^{-4} x^{4}+0.0085 x^{3}-0.13 x^{2}+2.6 x+3.2 .
$$

The RCL and LCL of the horizontal displacement are shown with the monitoring data and fitting data. The monitoring frequency should be enhanced if the monitoring data is out of the RCL and $L C L$, which will ensure safety during excavation. As indicated in Figure 4, the horizontal displacement of CX4 is evaluated by the RCL and LCL criteria. Most of the monitoring data is within the control range, which means the excavation is safe. Only several monitoring data are out of the $R C L$ and $L C L$ region because the monitoring place is below the fourth supporting bracing, which is out of the constraint of supporting system. It should also be noted that the displacement of the retaining wall can be significantly increased with the fluctuation of groundwater level. The monitoring frequency should be strengthened.

\subsection{Evaluation of Ground Settlement with Excavation Time.} The ground settlement varying with excavation time in section A3-E3 is depicted in Figure 5(a). With the increasing of excavation time, the ground settlement accumulated with the excavation process. There occurs a slight ground heaving of $5 \mathrm{~mm}$ when the excavation processing is 20 days. The 


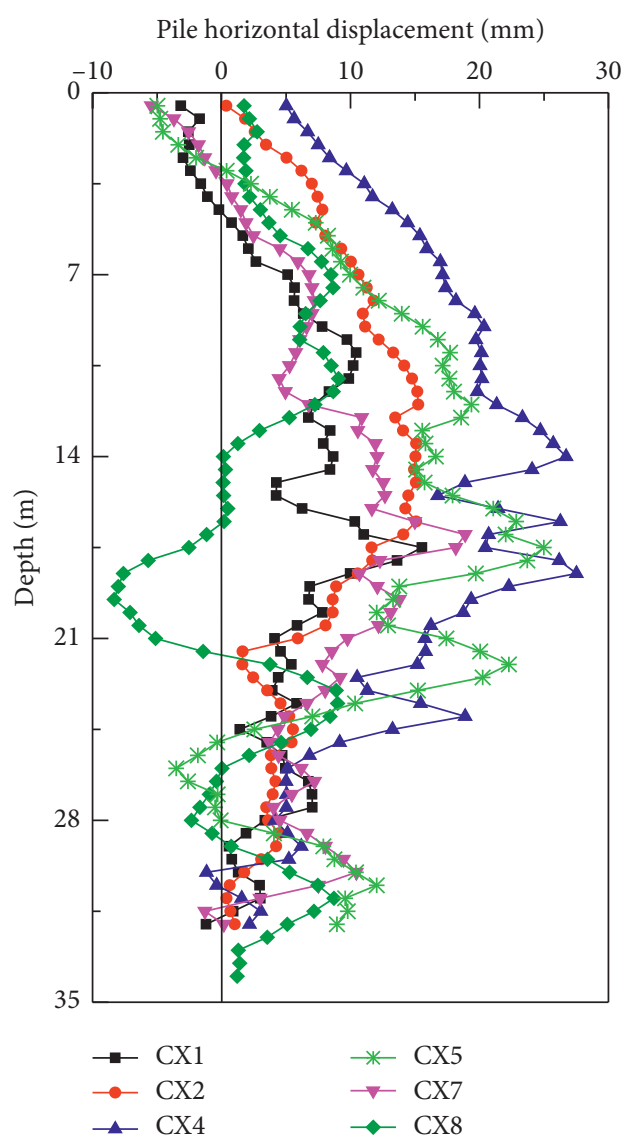

(a)

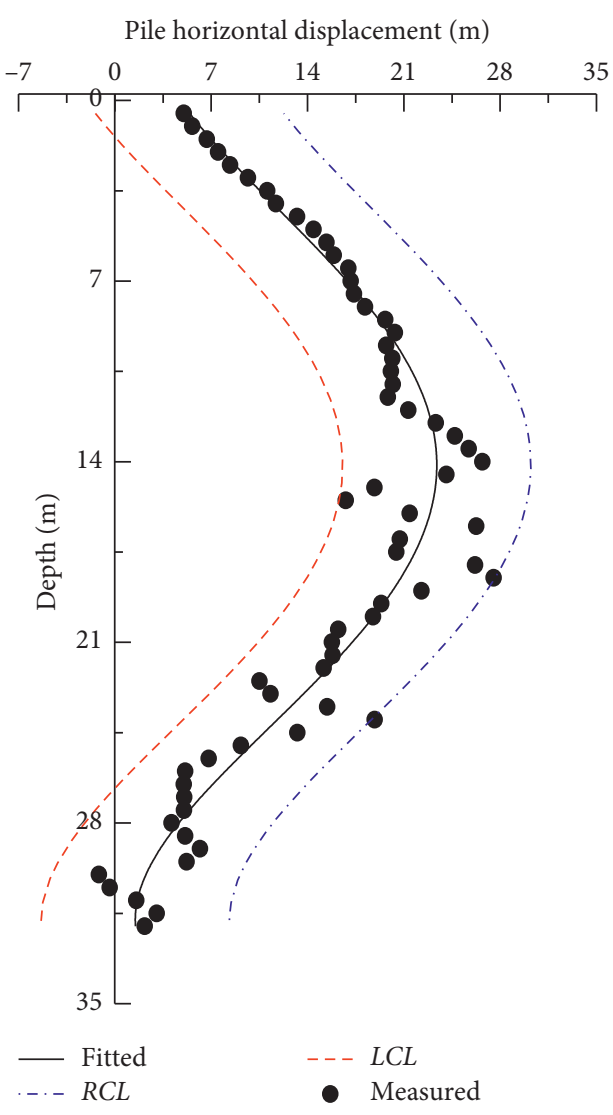

(b)

FIGURE 4: Final lateral displacement curves of CX4 pile body associated with control lines: (a) horizontal displacement; (b) control lines.

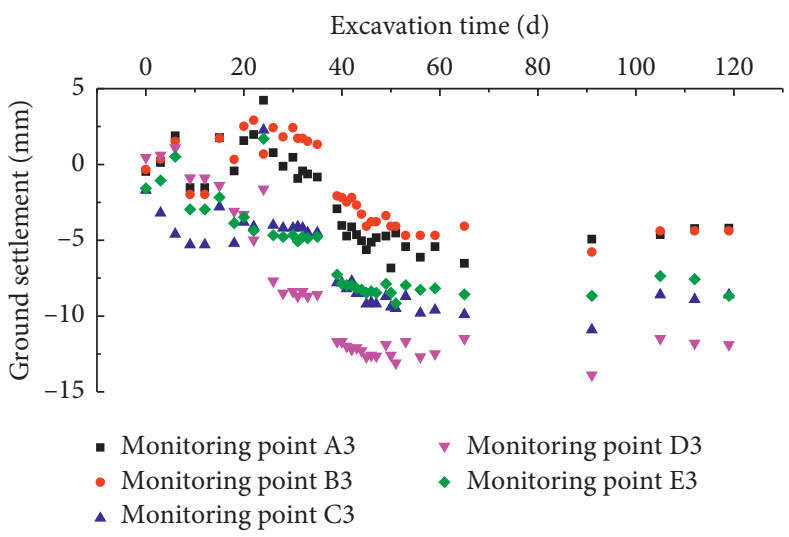

(a)

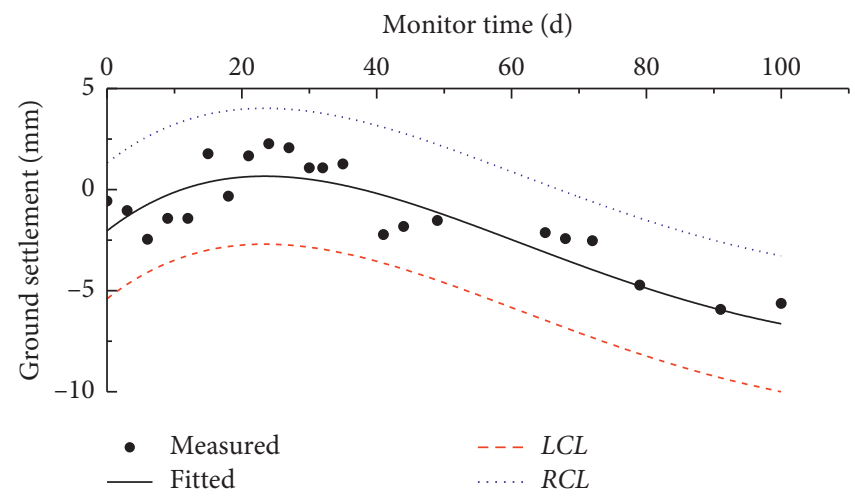

(b)

FIGURE 5: Ground settlement varying with (a) time in monitoring section A3-E3 and (b) control lines.

reason for this heaving is the adjustment of groundwater pumping, the groundwater level increasing results in a rebound of the ground in monitoring section $\mathrm{A} 3-\mathrm{E} 3$, and the total ground heaving is $4.23 \mathrm{~mm}$. The distance of monitoring point $\mathrm{A} 3$ to the excavation edge is $2 \mathrm{~m}$; the reinforced concrete between the soldier piles can effectively strengthen the ground soil. There is almost no ground settlement at the initial excavation period, the minimum ground settlement is 
$0.17 \mathrm{~mm}$, and the maximum ground settlement is $5 \mathrm{~mm}$ at the end of excavation. The ground settlement control value is $35 \mathrm{~mm}$. The maximum accumulated ground settlement at D3 is $13.89 \mathrm{~mm}$ which is $8 \mathrm{~m}$ far away from the excavation edge. The accumulated ground settlement decreases with the increase of distance from the excavation edge. With the analysis of the ground settlement monitoring data, the largest ground settlement is located from a distance from 22 to $30 \mathrm{~m}$ (about $1.0-1.3 \mathrm{H}$ ) with the accumulated ground settlement of $13.89 \mathrm{~mm}$. The least square method is adopted to fitting the ground settlement at monitoring line 3, monitoring point $\mathrm{C} 3$, which is located at the centre of the excavation long side (Figure 5(b)). A quartic polynomial expression is introduced to fitting the settlement rule, as shown in equation (8). The RCL and LCL criteria are further applied to evaluate the ground settlement, and the results prove that the excavation is in a safe condition:

$$
y=-1.59 e^{-7} x^{4}+6.03 e^{-5} x^{3}-0.0075 x^{2}+0.26 x+2.04 .
$$

\subsection{Evaluation of Ground Settlement of Adjacent Soil with the} Distance from Excavation Side. Monitoring Sections 1, 5, 7, and 9 are selected to reveal the rule of accumulated ground settlement and influence range with the excavation process (see Figure 6). The maximum ground settlement occurs at a vertical distance of $22 \mathrm{~m}$ from the long excavation side. A conclusion can be drawn that the main influence area is with $0.8 \mathrm{H}$, which coincides with the results by Zheng and Li [27] and $\mathrm{Ou}$ et al. [28].

Eight vertical distances, i.e., $2 \mathrm{~m}, 8 \mathrm{~m}, 14 \mathrm{~m}, 22 \mathrm{~m}, 30 \mathrm{~m}$, $40 \mathrm{~m}, 50 \mathrm{~m}$, and $70 \mathrm{~m}$, from the excavation are selected based on the monitoring line laid along with the excavation. It can be indicated that the ground settlement keeps constant when the distance from the excavation is more significant than $30 \mathrm{~m}$. The minimum ground settlement at $70 \mathrm{~m}$ is $0.6 \mathrm{~mm}$. We can define that the influence area from 1.74 to $3 \mathrm{H}$ is the secondary influence area. There is almost 0 settlement away from the secondary influence area.

It can be seen that the maximum ground settlement occurs at the centre of the long excavation side, i.e., monitoring line\#5. The RCL and LCL criteria are used to assess the safety of monitoring line\#5, and the ground settlement follows a power function rule (equation 9). As indicated in Figure 6(b), the ground settlement around the excavation is within the upper and lower control line. There is an abnormal point at $0.6 \mathrm{H}$, which means that the on-time warning of this monitoring part is necessary to ensure the safety of excavation:

$$
y=-30.55 e^{-0.5(x-22 / 4.93)^{2}}-3.49 .
$$

\section{Numerical Analysis of Parameters}

4.1. Model Description. The calculation model is set as a plainstrain problem. The horizontal direction is $X$, and the vertical direction is $Y$. The retaining piles and inner supporting follow the linear elastic rule; the internal support is using the truss element. Modified Mohr-Coulomb criteria are selected as the constitutive model of soil which can effectively consider the unloading deformation. The excavation dewatering is conducted before the excavation, so the draining process during excavation is neglected. Contact pairs are used between piles and soil to deal with two different materials.

To eliminate the influence of the boundary effect, the model size is set as $250 \mathrm{~m}(10 \mathrm{~B})$ and $125 \mathrm{~m}(5 \mathrm{D})$. The soil is constrained in both $X$ and $Y$ direction at the bottom, the model is constrained at $X$ direction at both sides, and the ground surface is set to be free surface. The initial ground stress is from soil gravity. Delaunay triangular and quadrilateral mesh is selected to improve computing efficiency. The mesh near the excavation is dense, and the other is coarse. There are 1576 elements and 1481 nodes in the whole model. The total excavation depth is $25 \mathrm{~m}$; there are four steps: $7 \mathrm{~m}, 7 \mathrm{~m}, 4 \mathrm{~m}$, and $7 \mathrm{~m}$, the inner support is laid after $1 \mathrm{~m}$ excavation depth. The inner support bracing will be active after excavation, as shown in Figure 7 . Through geological investigation report, the distribution of soil layers and physical-mechanical parameters are shown in Table 2.

4.2. Model Verification. The spatial effect of the excavation can be reflected by the horizontal displacement of retaining piles. The maximum horizontal displacement of retaining piles is closely related to the stability of the excavation. Monitoring data in CX pile is selected to reveal the variation of pile horizontal displacement with excavation time. The horizontal displacements of monitoring points CX1, CX2, CX4, CX5, CX7, CX8 are selected to compare with the numerical results.

As indicated in Figure 8, the horizontal displacement of piles varies with excavation time, and depth is depicted to reveal the variation rule. The horizontal displacement of piles increases with the excavation depth and excavation time. At the initial excavation period (0-30 days), the maximum pile horizontal displacement is $0.55 \mathrm{~mm}$, which is very small. At the middle period (30 to 90 days) after excavation, the excavation depth is $6.5 \mathrm{~m}$ to $19.5 \mathrm{~m}$ with a total excavation depth of $13 \mathrm{~m}(0.5 \mathrm{H})$; the horizontal displacement of piles shows a dramatic increase which almost reaches the maximum. When the excavation time reaches 60 days, the horizontal displacement of the pile suddenly increases to $12.59 \mathrm{~mm}$; the displacement velocity is $0.40 \mathrm{~mm} / \mathrm{d}$. At the excavation time of 90 days, the horizontal displacement of the pile increases to $22.52 \mathrm{~mm}$ with a displacement velocity of $0.33 \mathrm{~mm} / \mathrm{d}$. At the final stage of excavation $(120 \mathrm{~d})$, the horizontal displacement of the pile reaches the peak value of $26.72 \mathrm{~mm}$ with a velocity of $0.08 \mathrm{~mm} / \mathrm{d}$. The numerical result of the retaining pile shows a good agreement with the field measurements, which means that the numerical model can be used to study the optimum pile parameters of retaining piles.

4.3. Soil Earth Pressure at the Different Excavation Stages. The soil earth pressure distribution is displayed in Figure 9. The soil Earth pressure is linearly increasing after the first 


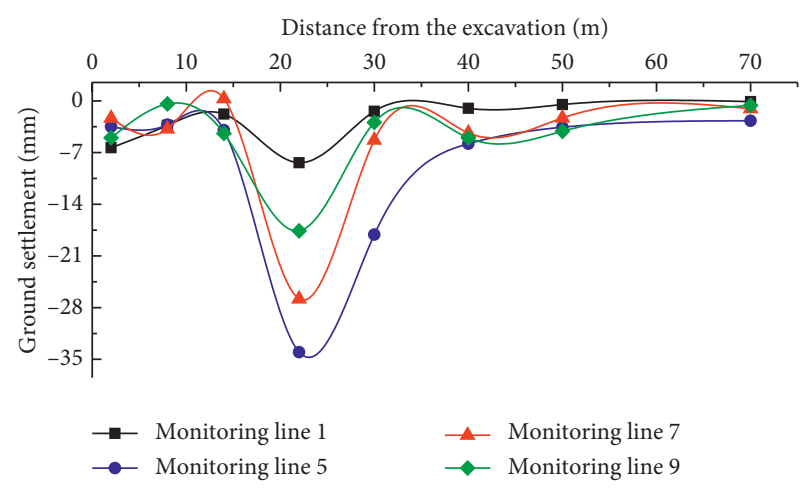

(a)

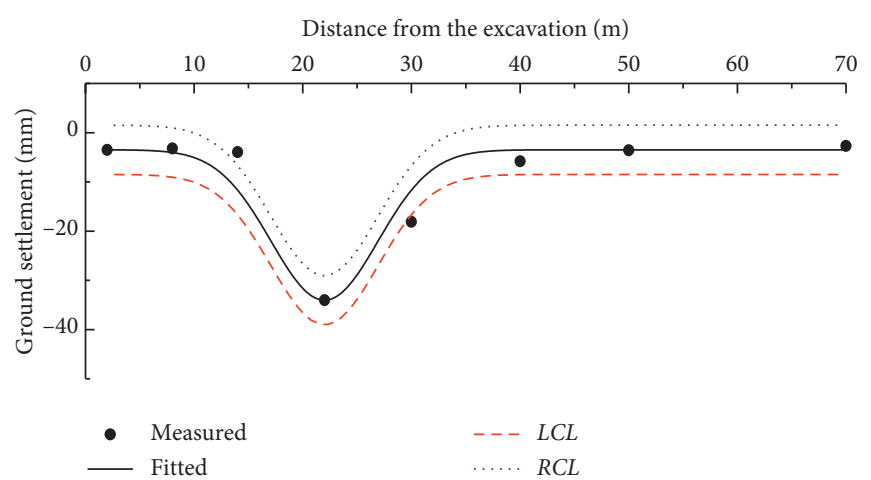

(b)

FIGURE 6: Ground settlement varying with (a) different settlement monitoring points and (b) control lines.

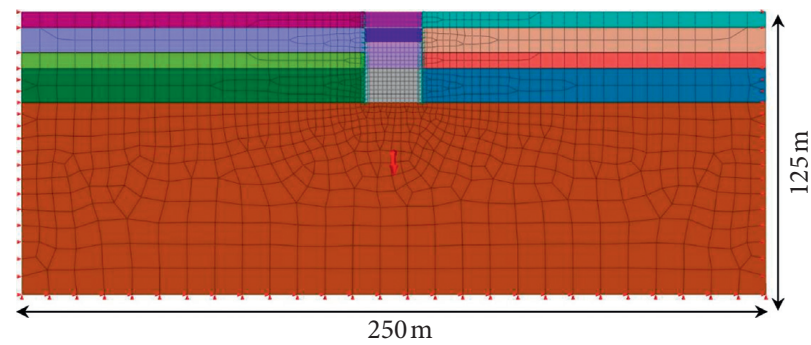

Figure 7: The finite element model.

TABLE 2: Physical and mechanical parameters of surrounding soils.

\begin{tabular}{lcccc}
\hline Types of soils & The thickness of the soil layer $(\mathrm{m})$ & Natural density $\left(\mathrm{kN} \cdot \mathrm{m}^{-3}\right)$ & Cohesion $(\mathrm{kPa})$ & Internal friction angle $\left(^{\circ}\right)$ \\
\hline Miscellaneous soil & 3.85 & 18.5 & 10 & 5.0 \\
Silty clay & 2.25 & 18.5 & 3 & 6.5 \\
Medium coarse sand & 5.4 & 17.5 & 2 & 29.6 \\
Gravel sand & 5.8 & 20.3 & 2 & 33.0 \\
Pebble & 5.3 & 20.5 & 34.0 \\
\hline
\end{tabular}

excavation period, which is close to the distribution of earth pressure at rest. With the excavation processing, the active earth pressure along the depth shows a slight increase below the inner support; the active earth pressure at a depth of $10 \mathrm{~m}$ is constrained by the first and second internal support. The third internal support effectively decreases the soil earth pressure at a depth of $15 \mathrm{~m}$ while the soil earth pressure increases significantly below the inner support. For the last excavation period, the active earth pressure within the excavation depth is effectively constrained by the inner support. The decrease of soil earth pressure distribution with the excavation depth is because of the inner support installed after each step of excavation; the increase of axial force from the inner support bracing can ensure the stability of the excavation.

\subsection{Optimization of Pile Parameters}

4.4.1. Study on Different Pile Diameters. The control values of ground settlement $(35 \mathrm{~mm})$ and the horizontal displacement of the pile $(50 \mathrm{~mm})$ are introduced to optimize the pile diameters. The pile diameters are set to be in a reasonable range from $0.7 \mathrm{~m}$ to $1.5 \mathrm{~m}$. As we can see from
Figure 10, the maximum ground settlement and the horizontal displacement of the pile decrease from $19.4 \mathrm{~mm}$ and $33.1 \mathrm{~mm}$ to $11.0 \mathrm{~mm}$ and $19.3 \mathrm{~mm}$, respectively, with the pile diameter increasing from $0.8 \mathrm{~m}$ to $1.0 \mathrm{~m}$. The maximum ground settlement and pile horizontal displacement decrease from $11.0 \mathrm{~mm}$ and $19.3 \mathrm{~mm}$ to $8.0 \mathrm{~mm}$ and $14.5 \mathrm{~mm}$, respectively, when the pile diameter increases from $1.0 \mathrm{~m}$ to $1.5 \mathrm{~m}$. The relative increasing rate is introduced to define the effect of pile diameter.

A relative parameter $R$ is defined as $R=\left(S_{1}-S_{\mathrm{s}}\right) / S_{1}$, where $S_{1}$ is the displacement of ground or piles at large pile diameter and $S$ s is the movement of ground or piles at small pile diameter. The results show that $R$ decreases from $21.58 \%$ and $20.85 \%$ to $5.46 \%$ and $4.98 \%$, respectively, with the increase of pile diameter. The optimal pile diameter should be set to $1.0 \mathrm{~m}$ to consider both the safety of the excavation and the construction cost. FEM method should be used before the construction to give some useful guidance on the construction. The maximum ground settlement decreases with the increase of pile diameter and follows an exponential function.

The relationship between maximum ground settlement and horizontal displacement of piles with diameters is 


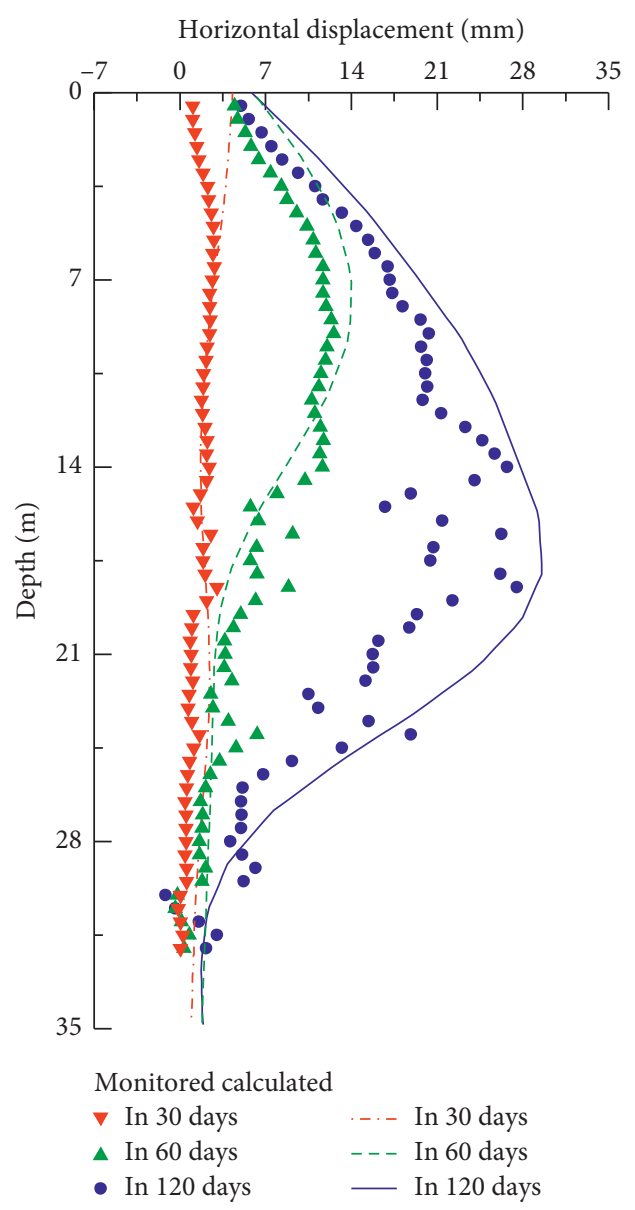

FIGURE 8: Lateral displacement of retaining pile body.

$$
\begin{aligned}
& y_{h}=140-1400 \times 0.004^{x}, \\
& y_{g}=7.8-737 \times 0.005^{x},
\end{aligned}
$$

where $y_{h}$ is the horizontal displacement of piles, $y_{g}$ is the vertical displacement of ground settlement, and $x$ is the pile diameter.

4.4.2. Study on Different Pile Lengths. The excavation depth $H_{\mathrm{e}}=25 \mathrm{~m}$ and the length of retaining piles is set to be $25 \mathrm{~m}$, $30 \mathrm{~m}, 35 \mathrm{~m}, 38 \mathrm{~m}$, and $40 \mathrm{~m}$ with other parameters kept constant, which means that the built-in depth $H_{\mathrm{b}}$ is $0,2.5 \mathrm{~m}$, $5 \mathrm{~m}, 10 \mathrm{~m}, 13 \mathrm{~m}$, and $15 \mathrm{~m}$. The embedded ratio $(e)$ of retaining pile is defined as the built-in depth over the excavation depth, i.e., $e=H_{\mathrm{b}} / H_{\mathrm{e}}$. The maximum ground settlement and pile horizontal displacement are observed under different $e=0,0.1,0.2,0.4,0.52$, and 0.6 (Figure 11). As it can be seen from the figure, the displacement of retaining structure and surrounding soil gradually decreases with the increasing of embedment ratio. At the same time, it turns to a constant value when the embedment ratio is larger than 0.4 . Therefore, $e=0.4$ is the optimum value for embedment in granular area.

The relationship between maximum ground settlement and horizontal displacement of pile follows a power distribution rule with an expression of

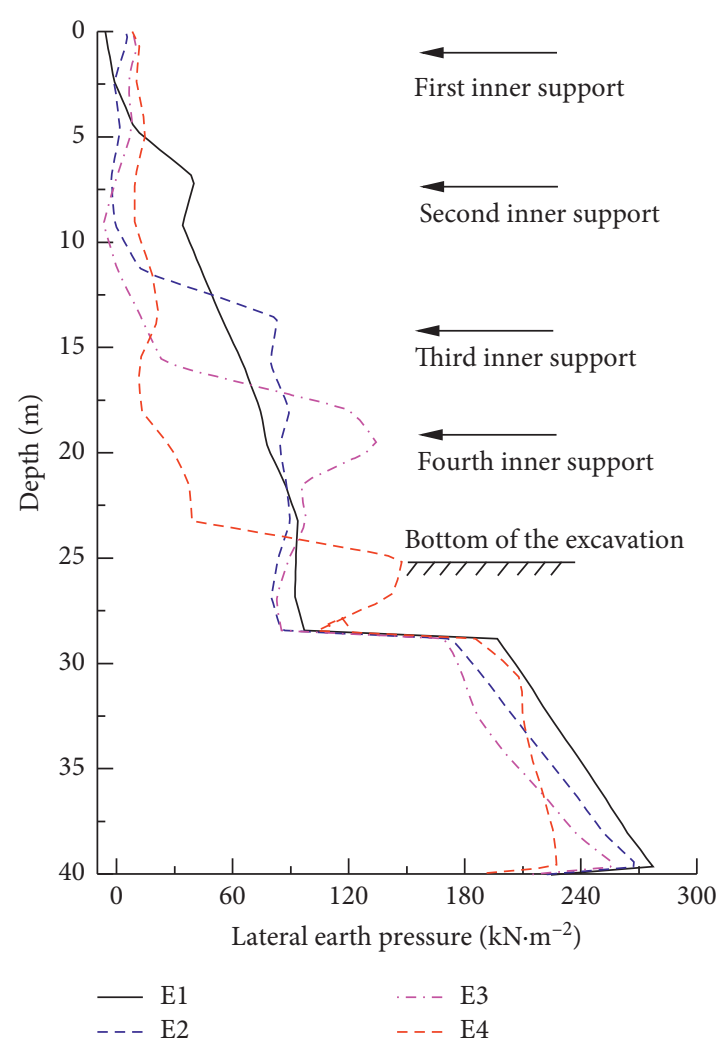

FIgURE 9: Soil Earth pressure of different excavation stage.

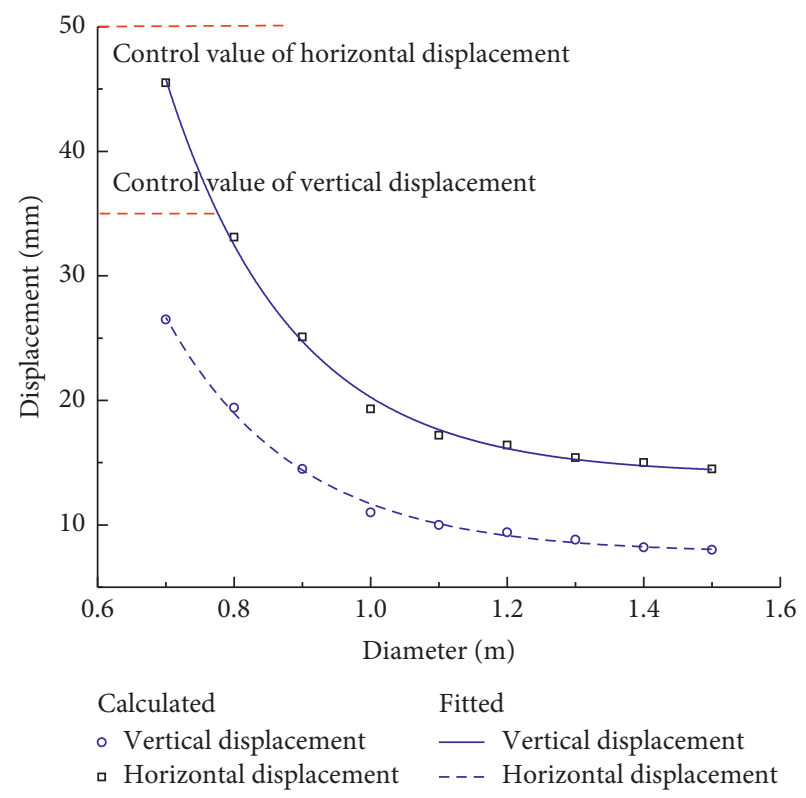

FIGURE 10: The influence of pile diameter on maximum displacement.

$$
\begin{aligned}
& y_{h}=10.5-6 \times 0.002^{x}, \\
& y_{g}=16.1-10 \times 0.0005^{x},
\end{aligned}
$$

where $y_{h}$ is the horizontal displacement of piles, $y_{g}$ is the vertical displacement of ground settlement, and $x$ is the embedment ratio. 


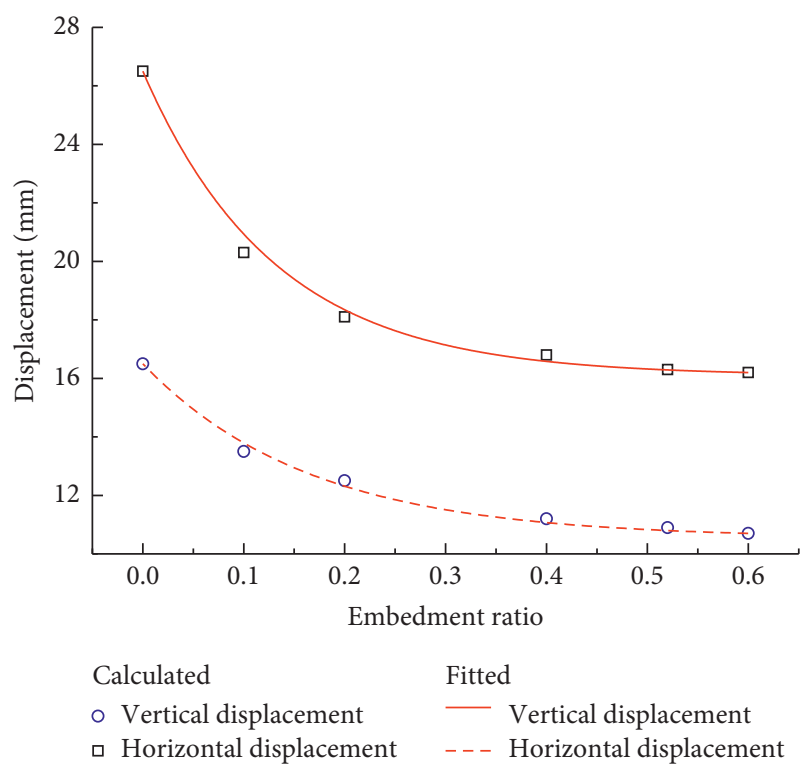

FIGURE 11: The influence of the pile embedment ratio on maximum displacement.

4.4.3. Study on Different Pile Rows. Single-row piles and double-row piles are installed to investigate the effect of different retaining piles on the response of deep excavation. The vertical displacement of soil and horizontal displacement of piles are extracted with different pile diameters. It is indicated that the double-row piles can effectively decrease the responses of deep excavation, as shown in Figure 12. The vertical and horizontal displacement of surrounding soil and retaining piles are decreasing with the increasing of pile rows as well as the pile diameters. While the deformation of retaining structure and surrounding soil keeps constant when the pile diameter is larger than $1.0 \mathrm{~m}$, the increasing of pile row can effectively decrease the horizontal displacement of retaining piles. This effect is more significant when the pile diameter is smaller; for example, the horizontal displacement and vertical displacement decrease roughly $32.5 \%$ and $21.4 \%$ compared to the control value when the pile diameter is $0.7 \mathrm{~m}$, while this value is $18 \%$ and $8.5 \%$ when the pile diameter is $1.5 \mathrm{~m}$.

The relationship between the vertical displacements of surrounding soil for single-row pile and double-row pile is

$$
\begin{aligned}
& y_{g s}=14-927 \times 0.008^{x}, \\
& y_{g d}=7.6-413 \times 0.01^{x} .
\end{aligned}
$$

The relationship between the horizontal displacements of piles for single-row pile and double-row pile is

$$
\begin{aligned}
& y_{h s}=6.8-734 \times 0.006^{x}, \\
& y_{h d}=5.6-335 \times 0.01^{x},
\end{aligned}
$$

where $y_{h s}$ and $y_{h d}$ are the horizontal displacement of singlerow piles and double-row piles, respectively, $y_{g s}, y_{g d}$ is the vertical displacement of ground settlement, and $x$ is the pile diameter.

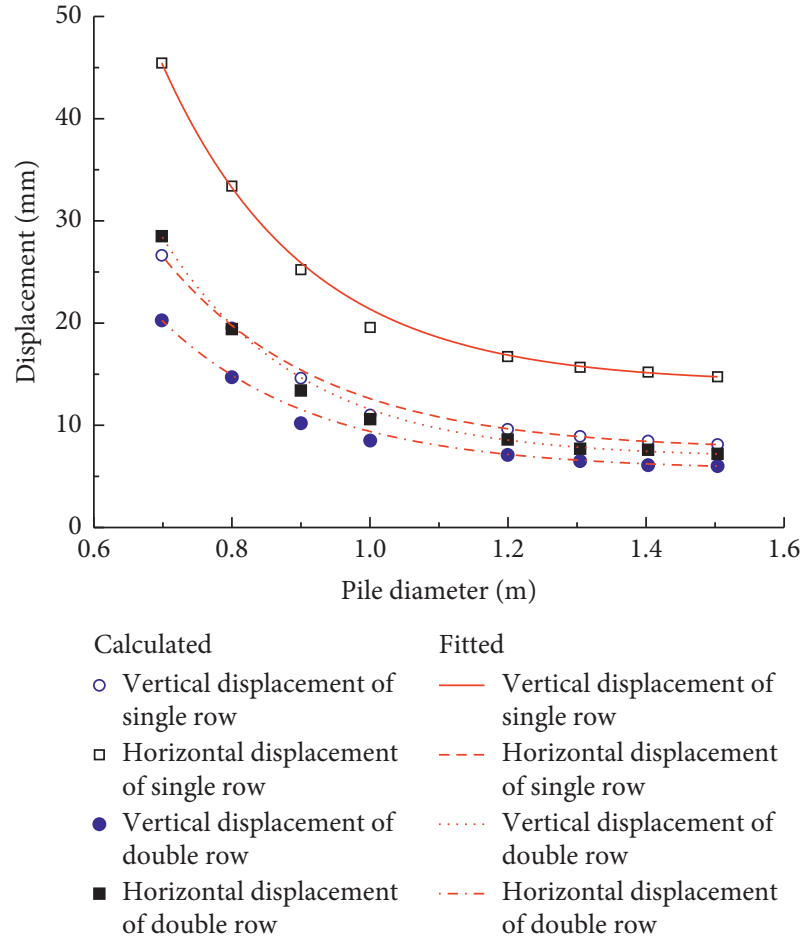

FIgURE 12: The influence of different pile rows on maximum displacement.

\section{Conclusion}

An excavation case in granular soils is used to evaluate the stability of deep excavation using displacement least squares method. Subsequently, the finite element method is used to optimize the critical parameters of the supported piles, and it needs to be emphasized that the correctness and reasonability of the FE models are evaluated according to field measurements. Some conclusions can be obtained, as follows.

Vertical displacement of surrounding soil and horizontal displacement of retaining piles are the most important indices for the stability of deep excavation. The stability of excavation using pile inner supporting system can be evaluated by adopting the least square method. The optimum pile diameter and embedment ratio for single- and double-row retaining pile are $1.0 \mathrm{~m}$ and 0.4 . The maximum vertical displacement of surrounding soil and horizontal displacement of piles can be calculated by the equations obtained in this research which can provide useful guidance for the designing of deep excavation.

\section{Data Availability}

The data used to support the findings of this study are included in the article.

\section{Conflicts of Interest}

The authors declare no conflicts of interest. 


\section{Acknowledgments}

This work was supported by the National Natural Science Foundation of China (Grant no. 51878127).

\section{References}

[1] W. Liu, P. Shi, G. Cai, and P. Gan, "A three-dimensional mechanism for global stability of slurry trench in frictional soils," European Journal of Environmental and Civil Engineering, vol. 2, pp. 1-26, 2019.

[2] W. Liu, P. Shi, H. Li, and F. Wang, "Observed performance of three adjacent $48 \mathrm{~m}$ depth concrete diaphragm wall panels in silty soils," Canadian Geotechnical Journal, vol. 56, no. 11, pp. 1736-1742, 2019.

[3] P. X. Shi, W. Liu, and J. L. Pan, "Experimental and analytical study of jacking load during microtunneling gongbei tunnel pipe roof," Journal of Geotechnical and Geoenvironmental Engineering, vol. 144, no. 1, Article ID 05017006, 2018.

[4] P. Jia, W. Zhao, A. Khoshghalb et al., "A new model to predict ground surface settlement induced by jacked pipes with flanges," Tunnelling and Underground Space Technology, vol. 98, Article ID 103330, 2020.

[5] P. Shi, D. Zhang, J. Pan, and W. Liu, "Geological investigation and tunnel excavation aspects of the weakness zones of Xiang'an subsea tunnels in China," Rock Mechanics and Rock Engineering, vol. 49, no. 12, pp. 4853-4867, 2016.

[6] J.-Y. Han, W. Zhao, P.-J. Jia, Y.-P. Guan, Y. Chen, and B.-F. Jiang, "Risk analysis of the opening of shield-tunnel circumferential joints induced by adjacent deep excavation," Journal of Performance of Constructed Facilities, vol. 32, no. 1, p. 04017123, 2018.

[7] W. Liu, P. Shi, L. Chen, and Q. Tang, "Analytical analysis of working face passive stability during shield tunneling in frictional soils," Acta Geotechnica, vol. 15, no. 3, pp. 781-794, 2020.

[8] P. J. Jia, A. Khoshghalb, and C. Chen, "A modified duncanchang constitutive model for modelling supported excavations in granular soils," International Journal of Geomechanics, 2020, In press.

[9] W. Zhao, J. Y. Han, and Y. Chen, "A numerical study on the influence of anchorage failure for a deep excavation retained by anchored pile walls," Advances in Mechanical Engineering, vol. 10, no. 2, Article ID 2072044765, 2018.

[10] J. F. Roboski and R. J. Finno, “Three-dimensional responses of a tied-back excavation through clay," Journal of Geotechnical and Geoenvironmental Engineering, vol. 131, no. 3, pp. 273282, 2005.

[11] Y. M. A. Hashash, A. Osouli, and C. Marulanda, "Central artery/tunnel project excavation induced ground deformations," Journal of Geotechnical and Geoenvironmental Engineering, vol. 134, no. 9, pp. 1399-1406, 2008.

[12] B. Wei and Y. Tan, "Observed behaviors of a long and deep excavation constructed by cut-and-cover technique in shanghai soft clay," Journal of Geotechnical and Geoenvironmental Engineering, vol. 138, no. 1, pp. 69-88, 2012.

[13] E. Momeni, M. Poormoosavian, A. Mahdiyar, and A. Fakher, "Evaluating random set technique for reliability analysis of deep urban excavation using monte Carlo simulation," Computers and Geotechnics, vol. 100, pp. 203-215, 2018.

[14] M. Huang, Z. Tang, and J. Yuan, "Basal stability analysis of braced excavations with embedded walls in undrained clay using the upper bound theorem," Tunnelling and Underground Space Technology, vol. 79, pp. 231-241, 2018.
[15] J.-Y. Han, W. Zhao, Y. Chen, P.-J. Jia, and Y.-P. Guan, "Design analysis and observed performance of a tieback anchored pile wall in sand," Mathematical Problems in Engineering, vol. 2017, pp. 1-23, 2017.

[16] Y. Chen, W. Zhao, P.-J. Jia, and J.-Y. Han, "Proportion analysis of ground settlement caused by excavation and dewatering of a deep excavation in sand area," Indian Geotechnical Journal, vol. 48, no. 1, pp. 103-113, 2018.

[17] H.-C. Yeow, D. Nicholson, C.-L. Man, A. Ringer, P. Glass, and M. Black, "Application of observational method at crossrail tottenham court road station, UK," Proceedings of the Institution of Civil Engineers - Geotechnical Engineering, vol. 167, no. 2, pp. 182-193, 2014.

[18] J. Spross and F. Johansson, "When is the observational method in geotechnical engineering favourable?" Structural Safety, vol. 66, pp. 17-26, 2017.

[19] P. Jia, W. Zhao, X. Du et al., "Study on ground settlement and structural deformation for large span subway station using a new pre-supporting system," Royal Society Open Science, vol. 6, no. 2, p. 181035, 2019.

[20] P.-J. Jia, W. Zhao, Y. Chen, S.-G. Li, J.-Y. Han, and J.-C. Dong, "A case study on the application of the steel tube slab structure in construction of a subway station," Applied Sciences, vol. 8, no. 9, p. 1437, 2018.

[21] R. Fuentes, A. Pillai, and P. Ferreira, "Lessons learnt from a deep excavation for future application of the observational method," Journal of Rock Mechanics and Geotechnical Engineering, vol. 10, no. 3, pp. 468-485, 2018.

[22] A. Alipour and A. Eslami, "Design adaptations in a large and deep urban excavation: case study," Journal of Rock Mechanics and Geotechnical Engineering, vol. 11, no. 2, pp. 389-399, 2019.

[23] P. C. Prat, "Numerical investigation into the failure of a micropile retaining wall," Computers and Geotechnics, vol. 81, pp. 262-273, 2017.

[24] A. Lim and C.-Y. Ou, "Stress paths in deep excavations under undrained conditions and its influence on deformation analysis," Tunnelling and Underground Space Technology, vol. 63, pp. 118-132, 2017.

[25] P. Ni, G. Mei, Y. Zhao, and H. Chen, "Plane strain evaluation of stress paths for supported excavations under lateral loading and unloading," Soils and Foundations, vol. 58, no. 1, pp. 146-159, 2018.

[26] C. Wang, Y. Zhu, and Q. Zhang, "Monitoring analysis and stability evaluation of pile-bolt support system in deep pit," Chinese Journal of Rock Mechanics and Engineering, vol. 33, no. S1, pp. 2918-2923, 2014.

[27] G. Zheng and Z. W. Li, "Finite element analysis of adjacent building response to corner effect of excavation," Journal of Tianjin University, vol. 45, no. 8, pp. 688-699, 2012.

[28] C.-Y. Ou, J.-T. Liao, and H.-D. Lin, "Performance of diaphragm wall constructed using top-down method," Journal of Geotechnical and Geoenvironmental Engineering, vol. 124, no. 9, pp. 798-808, 1998. 